\title{
Midterm patency rate after saphenous vein grafting with a PAS-Port device
}

\author{
Masashi Kai, MD, Michiya Hanyu, MD, Yoshiharu Soga, MD, Takuya Nomoto, MD, Jota Nakano, MD, Takehiko Matsuo, MD, \\ Masahide Kawato, MD, and Hitoshi Okabayashi, MD, Fukuoka, Japan
}

Recently, a new proximal anastomosis device of a saphenous vein graft (SVG) to the aorta, the PAS-Port device (Cardica, Redwood City, Calif) has been introduced and yielded encouraging results in terms of neurologic complications and early patency. ${ }^{1,2}$ However, there is a concern about the midterm (at least 1 year after surgical intervention) patency rate. The aim of this study was to evaluate the midterm patency rate of SVGs whose proximal anastomosis was performed with the PAS-Port device.

\section{CLINICAL SUMMARY}

Between January 2004 and September 2006, 69 PAS-Port devices had been used in 66 patients undergoing SVG proximal anastomosis in coronary artery bypass grafting (CABG) at Kokura Memorial Hospital. Sixty-three patients had off-pump grafting, and 3 patients had on-pump beatingheart grafting. The details of the operative data are summarized in Table 1. Bilateral internal thoracic artery grafting for the left coronary territory was our standard method. The gastroepiploic artery was our first choice for revascularization of the right coronary artery territory. We used SVGs when (1) stenosis of the native coronary artery was mild $(<90 \%),(2)$ arterial conduits had already been used in previous operations, (3) emergency operations were necessary, and (4) the patient had a prior history of gastrointestinal disorders. The proximal anastomosis devices were used basically in case the ascending aorta showed atheromatous changes on an epiaortic echocardiogram. Additional 40 Prolene purse-string stitching around the deployed device was performed in $15(21.7 \%)$ of 69 devices to control the bleeding. No patients had difficulty achieving the hemostasis. All the operations were performed by one experienced surgeon. Every patient was given a subcutaneous heparin injection on postoperative days 1 to 4 to prevent postoperative stroke and perioperative myocardial infarction. Oral aspirin was started on postoperative day 1 and continued throughout the follow-up period. No 30-day mortality or intraoperative

\footnotetext{
From the Department of Cardiovascular Surgery, Kokura Memorial Hospital, Fukuoka, Japan.

Received for publication Dec 5, 2007; revisions received Jan 29, 2008; accepted for publication March 2, 2008.

Address for reprints: Masashi Kai, MD, Department of Cardiovascular Surgery, Kokura Memorial Hospital, 1-1 Kifunemachi Kokurakita-ku, Kitakyushu, Fukuoka, 8020073 Japan (E-mail: m-kai@db4.so-net.ne.jp).

J Thorac Cardiovasc Surg 2009;137:503-4

$0022-5223 / \$ 36.00$

Copyright (c) 2009 by The American Association for Thoracic Surgery

doi:10.1016/j.jtcvs.2008.03.006
}

TABLE 1. Operative data $(n=66)$

\begin{tabular}{lc}
\hline Age $(\mathrm{y})$, mean \pm SD & $69.7 \pm 10.3$ \\
Female sex, $\mathrm{n}(\%)$ & $16(24.2 \%)$ \\
Comorbidity, $\mathrm{n}(\%)$ & \\
Hypertension & $42(63.6)$ \\
Hyperlipidemia & $34(51.5)$ \\
Diabetes & $25(37.9)$ \\
Peripheral vascular disease & $9(13.6)$ \\
Dialysis & $14(21.2)$ \\
Cerebrovascular disease & $8(12.1)$ \\
Previous coronary intervention & $25(37.9)$ \\
Previous myocardial infarction & $23(34.8)$ \\
Unstable angina & $17(25.8)$ \\
Ejection fraction $<40 \%$ & $6(9.1)$ \\
Left main trunk disease & $24(36.4)$ \\
Three-vessel disease & $47(71.2)$ \\
Emergency procedure & $10(15.1)$ \\
Redo procedure & $4(6.1)$ \\
Preoperative IABP & $4(6.1)$ \\
BITA grafting & $41(62.1)$ \\
Off-pump & $63(95.6)$ \\
No. of distal anastomoses, mean \pm SD & $3.7 \pm 1.2$ \\
Details of saphenous vein grafting, $\mathrm{n}(\%)$ & \\
Endoscopic harvesting & $12(17.4)$ \\
Sequential grafting & $26(37.7)$ \\
Target coronary artery, $\mathrm{n}(\%)$ & \\
Left anterior descending artery & $8(11.6)$ \\
Circumflex artery & $11(15.9)$ \\
Right coronary artery & $43(62.3)$ \\
Right coronary artery and circumflex artery & $7(10.1)$ \\
Degree of stenosis, $\mathrm{n}(\%)$ & \\
$90 \%<$ & $34(49.3)$ \\
L5\% > & $35(50.7)$ \\
Ascending aorta & $68(98.6)$ \\
Descending aorta & $1(1.4)$ \\
\hline
\end{tabular}

$S D$, Standard deviation; IABP, intra-aortic balloon pump; BITA, bilateral internal thoracic artery.

stroke was observed. Six patients died within 1 year after the operation. Among them, 2 deaths were due to cardiac causes: congestive heart failure $(\mathrm{n}=1)$ and sudden death $(\mathrm{n}=1)$. The other 4 deaths were due to noncardiac reasons: cancer $(n=2)$, sepsis $(n=1)$, and liver failure $(n=1)$. Of 46 midterm survivors (at least 1 year after surgical intervention), $38(82.6 \%)$ consented to late follow-up graft evaluation by means of 3-dimensional computed tomography. Two of 39 devices were occluded, and the 1-year patency rate (FitzGibbon grade A) was 94.9\%. No obvious stenosis 
TABLE 2. Details of the occluded saphenous vein grafts

\begin{tabular}{|c|c|c|c|c|c|c|}
\hline & $\begin{array}{c}\text { Preoperative } \\
\text { characteristics }\end{array}$ & $\begin{array}{l}\text { Endoscopic } \\
\text { harvesting }\end{array}$ & $\begin{array}{c}\text { Sequential } \\
\text { grafting }\end{array}$ & $\begin{array}{c}\text { Target } \\
\text { coronary artery }\end{array}$ & $\begin{array}{c}\text { Degree of } \\
\text { stenosis }\end{array}$ & $\begin{array}{c}\text { Location of the } \\
\text { proximal anastomosis }\end{array}$ \\
\hline 73-year-old man & Diabetes & No & No & $\mathrm{RCA}$ & $75 \%$ & Ascending aorta \\
\hline 49-year-old man & Dialysis, diabetes, CVD & No & No & RCA & $90 \%$ & Ascending aorta \\
\hline
\end{tabular}

$R C A$, Right coronary artery; $C V D$, cerebrovascular disease.

of SVGs (FitzGibbon grade B) was observed. Of the 38 patients who underwent late graft evaluation, 24 did so at least 2 years after surgical intervention. The 2-year cumulative patency rate was $91.7 \%(22 / 24)$. All the results were evaluated by an experienced radiologist. Details of the occluded SVGs are given in Table 2.

\section{DISCUSSION}

Stroke is a devastating complication of CABG. Manipulation of the aorta using techniques such as crossclamping is thought to be a predisposing risk factor. The off-pump technique has brought more attention to reduce this devastating complication. Use of an aortic side clamp requires aortic manipulation, thereby precluding the major advantage of the off-pump technique. Several devices for proximal anastomosis of SVGs to the aorta have been developed and can facilitate clampless proximal anastomosis. Although the results have been satisfactory in terms of neurologic complications, there have been some concerns about early and longterm patency rates. The early patency rate of the previous generation of the proximal anastomosis device, the Symmetry device (St Jude Medical, Inc, Minneapolis, Minn), was satisfactory, but production was discontinued because of the poor midterm and long-term results. ${ }^{3-5}$ The PAS-Port device has the potential to yield better results than the Symmetry device for the following reasons: (1) the stents were located outside and not inside the SVG, which did not reduce the total amount of blood exposed to nonintimal surfaces inside the aortic lumen, and (2) the stents were composed of
316L medical grade stainless-steel and not nitinol, which can cause intimal hyperplasia. ${ }^{1}$

We realize that the gold standard for the evaluation of graft patency is angiography. It is relatively difficult to assess the details of anastomosis sites with computed tomography. Therefore we might have missed a number of stenotic vessels. In addition, this is a very small cohort of patients.

In conclusion, this study demonstrated the satisfactory results of midterm patency rate after placement of SVGs with a PAS-Port device. This device could be useful for $\mathrm{CABG}$ in case the ascending aorta showed the severe atheromatous change to a degree that precluded the use of a side clamp. However, a larger-scale study and a longer followup period will be mandatory to confirm the reliability of this device.

\section{References}

1. Gummert JF, Demertzis S, Matschke K, Kappert U, Anssar M, Siclari F, et al. Sixmonth angiographic follow-up of the PAS-Port II clinical trial. Ann Thorac Surg. 2006;81:90-6

2. Lahtinen J, Biancari F, Ojala R, Mosorin M, Cresti R, Rainio P, et al. Prospective, randomized study of the use of the cardiac PAS-Port aortic connector system in off-pump coronary artery bypass surgery. Heart Surg Forum. 2006;9:E568-71.

3. Kitamura H, Okabayashi H, Hanyu M, Soga Y, Nomoto T, Johno H, et al. Early and midterm patency of the proximal anastomoses of saphenous vein grafts made with a Symmmetry Aortic Connector System. J Thorac Cardiovasc Surg. 2005;130: 1028-31.

4. Reuthebuch OT, Kadner A, Lachat ML, Turina MI. Graft occlusion after deployment of the Symmetry bypass system. Ann Thorac Surg. 2003;75:1626-9.

5. Lahtinen J, Biancari F, Mosorin M, Heikkinen J, Rainio P, Juvonen TS, et al. Fatal complications after use of the symmetry aortic connector in coronary artery bypass surgery. Ann Thorac Surg. 2004;77:1817-9.

\title{
Late rupture of polytetrafluoroethylene neochordae after mitral valve repair
}

\author{
R. Saeid Farivar, MD, PhD, ${ }^{a}$ Stanton K. Shernan, MD, ${ }^{b}$ and Lawrence H. Cohn, $\mathrm{MD},{ }^{\mathrm{c}}$ Boston, Mass
}

From the Division of Cardiac Surgery, Department of Cardiothoracic Surgery, ${ }^{a}$ Department of Surgery, ${ }^{\mathrm{c}}$ and the Department of Anesthesiology, Perioperative and Pain Medicine, ${ }^{\mathrm{b}}$ Brigham \& Women's Hospital, Boston, Mass.

Received for publication Jan 31, 2008; accepted for publication Feb 13, 2008.

Address for reprints: Robert Saeid Farivar, MD, PhD, 200 Hawkins Dr lowa city, IA 52242 (E-mail: robert-farivar@uiowa.edu)

J Thorac Cardiovasc Surg 2009;137:504-6

$0022-5223 / \$ 36.00$

Copyright (C) 2009 by The American Association for Thoracic Surgery doi:10.1016/j.jtcvs.2008.02.053
Mitral valve repair is the procedure of choice to correct mitral regurgitation. The introduction of polytetrafluoroethylene (PTFE) sutures was an important contribution by David ${ }^{1}$ and Zussa and colleagues ${ }^{2}$ for the treatment of chordal shortening or for chordal replacement during mitral valve repair. This report describes a patient with acute-onset hematuria 11 years after mitral valve repair who was found to have fractured PTFE neochordae necessitating mitral valve replacement. 